\title{
Transperitoneal versus Extraperitoneal Laparoscopic Radical Prostatectomy During the Learning Curve: Does the Surgical Approach Affect the Complication Rate?
}

\author{
Tiberio M. Siqueira Jr., Anuar I. Mitre, Ricardo J. Duarte, Humberto Nascimento, Francualdo \\ Barreto, Evandro Falcao, Roberto I. Lopes, Miguel Srougi
}

Section of Urology (TMS, HN, EF, FB), Getulio Vargas Hospital, Recife, Pernambuco, Brazil and Division of Urology (TMS, AIM, RJD, RIL, MS), School of Medicine, University of Sao Paulo, Sao Paulo, Brazil

\begin{abstract}
Purpose: To compare the perioperative complication rate obtained with the transperitoneal laparoscopic radical prostatectomy (TLRP) and with the extraperitoneal LRP (ELRP) during the learning curve (LC).

Materials and Methods: Data of the initial 40 TLRP (Group 1) were retrospectively compared with the initial 40 ELRP (Group 2). Each Group of patients was operated by two different surgeons.

Results: The overall surgical time (175 min x $267.6 \mathrm{~min} ; \mathrm{p}<0.001)$ and estimated blood loss $(177.5 \mathrm{~mL} \times 292.4 \mathrm{~mL} ; \mathrm{p}<$ $0.001)$ were statistically better in the Group 1 . Two intraoperative complications were observed in Group 1 (5\%) represented by one case of bleeding and one case of rectal injury, whereas four complications (10\%) were observed in Group 2 , represented by two cases of bleeding, one bladder and one rectal injuries $(\mathrm{p}=0.675)$. Open conversion occurred once in each Group (2.5\%). Overall postoperative complications were similar $(52.5 \%$ x 35\%; $\mathrm{p}=0.365)$. Major early postoperative complications occurred in three and in one case in Group 1 and 2, respectively. Group 1 had two peritonitis (fecal and urinary), leading to one death in this group.

Conclusions: No statistical differences in overall complication rates were observed. The transperitoneal approach presented more serious complications during the early postoperative time and this fact is attributed to the potential chance of intraperitoneal peritonitis not observed with the extraperitoneal route.
\end{abstract}

Key words: prostate; prostatic neoplasms; prostatectomy; laparoscopy

Int Braz J Urol. 2010; 36: 450-7

\section{INTRODUCTION}

Since 1998, laparoscopic radical prostatectomy (LRP) has gained worldwide popularity, based on the Montsouris initial publication with the transperitoneal LRP (TLRP) (1) followed by the Brussels initial publication with the extraperitoneal approach (ELRP) (2).
It has been ten years and so far a debate related to the approach for performing LRP, mainly during the learning curve (LC), still remains. Some authors prefer the transperitoneal approach based on the larger working space and better luminosity and others prefer the extraperitoneal counterpart, based on the lack of contact with the intraperitoneal organs (3-6). 
Analyzing the comparative studies for LRP during the $\mathrm{LC}$, it can be noted that the vast majority of groups started their programs using the transperitoneal approach, switching later on to the extraperitoneal route (7-9). This observation generates a bias on results, once the findings of worse results with the transperitoneal approach when compared with the extraperitoneal approach is overlooked. The results observed with the TLRP in these studies reflect the suboptimal results found during the initial phase of a LRP program and the results achieved with the extraperitoneal approach are the reflex of an "already" well-trained surgical team.

The aim of this study was to compare the initial perioperative complications obtained with both approaches used to perform LRP and identify, if possible, a more suitable approach to use during the initial stages of a LRP program.

\section{MATERIALS AND METHODS}

This retrospective study was approved by each institutional research and ethical committee. The data of the first 40 TLRP performed between March, 2004 and November, 2007 (Group 1) performed at Getúlio Vargas Hospital of Recife were recorded and compared with the first 40 ELRP performed between August, 2003 and June, 2006 (Group 2) at Clinics Hospital of State University of São Paulo.

Each group was operated by only one experienced laparoscopic urologic surgeon in two uro-laparoscopic referral centers in this country. By the time of this study, each surgeon had already performed more than 250 laparoscopic surgeries, including partial nephrectomies, radical nephrectomies, donor nephrectomies, adrenalectomies, pyeloplasties and others. Inclusion criteria were age $\leq 75$ years old, clinically localized prostate tumors (cT1 and cT2N0M0), total $\mathrm{PSA} \leq 10 \mathrm{ng} / \mathrm{dL}$ and Gleason score $\leq 7$.

\section{Surgical Technique}

All TLRP were performed by the Montsouris technique (10) while the ELRP were done by the Brussels technique (2) with some modifications.
Briefly, in the Montsouris technique, the vas deferens and seminal vesicles were firstly dissected through the retrovesical space. After entering the Retzius space and opening the endopelvic fascia, the dorsal vein complex (DVC) was tied. The bladder neck was incised, reaching the pre-dissected vas deferens. Bilaterally, the prostatic pedicles were controlled and an interfascial neurovascular bundle dissection was performed whenever possible (11). Afterwards, the DVC and urethra were cut, leaving the prostate apart for later removal. A running urethrovesical (UV) anastomosis was made in all cases of Group 1 as described by van Velthoven et al. (12).

In the Brussels technique, the Retzius space was digitally created, avoiding transperitoneal entering. The other stages were about the same as transperitoneal approach, differing only in the straight access to vas deferens and seminal vesicles after bladder neck incision. An interrupted figure of " $\mathrm{X}$ " $\mathrm{UV}$ anastomosis was performed in all patients in Group 2.

\section{Pathological Evaluation}

All fine-needle biopsies and specimens were evaluated by the uro-pathology service of each institution. Positive surgical margin (PSM) was defined as the presence of tumor at the inked margin. Tumors were graded according to the Gleason score and pathological staging was based on TNM 1997 classification.

\section{Statistical Analysis}

Analysis of variance was used to compare continuous outcome variables between both groups. The Student's-t-test was used for homogeneous variances in each group and the Chi-square and Fisher's exact test were used to compare categorical outcome variables. Statistical significance was defined as $\mathrm{P}$ value $<0.05$.

\section{RESULTS}

Preoperative data are shown in Table-1. There was a statistical difference between groups 1 and 2, 
Table 1 - Preoperative results.

\begin{tabular}{lccc}
\hline & $\begin{array}{c}\text { Group 1 } \\
(\mathrm{n}=40)\end{array}$ & $\begin{array}{c}\text { Group 2 } \\
(\mathrm{n}=40)\end{array}$ & p Value \\
\hline Age (years) & $59.8 \pm 6.8(46-73)$ & $63.6 \pm 7.9(51-75)$ & $\mathrm{p}=0.011$ \\
PSA (ng/dL) & $5.4 \pm 2.02(2.0-10.0)$ & $5.9 \pm 1.96(2.0-9.9)$ & $\mathrm{p}=0.255$ \\
Prostatic weight (g) & $36.2 \pm 14.3(20-80)$ & $35.4 \pm 20.5(15-140)$ & $\mathrm{p}=0.846$ \\
Clinical stage - n (\%) & & & $\mathrm{p}=0.013$ \\
T1c & $32(80 \%)$ & $20(50 \%)$ & \\
T2a & $7(17.5 \%)$ & $15(37.5 \%)$ & \\
T2b & $1(2.5 \%)$ & $5(12.5 \%)$ & \\
Gleason score - n (\%) & - & $1(2.5 \%)$ & \\
$4(2+2)$ & - & $2(5 \%)$ & \\
$5(3+2)$ & $20(50 \%)$ & $32(80 \%)$ & \\
$6(3+3)$ & $14(35 \%)$ & $2(5 \%)$ & \\
$7(3+4)$ & $6(15 \%)$ & $3(7.5 \%)$ & \\
$7(4+3)$ & & & \\
\hline
\end{tabular}

PSA = prostate-specific antigen .

related to the patient's age, clinical stage and Gleason score. Clinical stage T1c was more common in Group $1(80 \%)$ while cT2 was prevalent in Group $2(50 \%)$. On the other hand, the Gleason score 7 was more prevalent in Group 1 (50\% x 12.5\%).

The intraoperative data are described in Table-2. Overall surgical time (175 min x $267.6 \mathrm{~min}$; $\mathrm{p}<0.001)$ and estimated blood loss $(177.5 \mathrm{~mL}$ x 292.4
$\mathrm{mL} ; \mathrm{p}<0.001$ ) were statistically significant better in the Group 1. Two complications (5\%) were observed in Group 1, represented by a bleeding from the DVC and rectal injury. The first one was controlled after conversion to the open approach and the last one was treated with intracorporeal suture. Four complications $(10 \%)$ occurred in Group 2, represented by two cases of bleeding $(5 \%)$, one bladder $(2.5 \%)$ and one

Table 2 - Comparison of intraoperative data.

\begin{tabular}{lccc}
\hline & $\begin{array}{c}\text { Group 1 } \\
(\mathrm{n}=40)\end{array}$ & $\begin{array}{c}\text { Group 2 } \\
(\mathrm{n}=40)\end{array}$ & p Value \\
\hline Overall operative time (min) & $\begin{array}{c}175.0 \pm 48.4 \\
(110-360)\end{array}$ & $\begin{array}{c}267.6 \pm 70.57 \\
(160-540)\end{array}$ & $\mathrm{p}<0.001$ \\
Blood loss (mL) & $177.5 \pm 148.5$ & $292.4 \pm 173.7$ & $\mathrm{p}<0.001$ \\
& $(50-1000)$ & $(10-900)$ & \\
Open conversion - n (\%) & $1(2.5 \%)$ & $2(5 \%)$ & $\mathrm{p}=1.000$ \\
Complications - $\mathrm{n}(\%)$ & & $4(10 \%)$ & $\mathrm{p}=0.675$ \\
Overall & $2(5 \%)$ & $2(5 \%)$ & \\
Complication type - $\mathrm{n}(\%)$ & $1(2.5 \%)$ & $1(2.5 \%)$ & \\
$\quad$ Bleeding & $1(2.5 \%)$ & $1(2.5 \%)$ & \\
Rectal injury & - & & \\
Bladder injury & &
\end{tabular}


Table 3 - Comparison of postoperative data.

\begin{tabular}{lccc}
\hline & $\begin{array}{c}\text { Group 1 } \\
(\mathrm{n}=40)\end{array}$ & $\begin{array}{c}\text { Group 2 } \\
(\mathrm{n}=40)\end{array}$ & p Value \\
\hline Time to discharge - (days)* & $3.0(3-35)$ & $3.0(2-17)$ & $\mathrm{p}=0.042$ \\
Early urinary continence - $\mathrm{n}(\%)$ & $27(69.2 \%)$ & $34(85 \%)$ & $\mathrm{p}=0.033$ \\
Sexual intercourse - $\mathrm{n}(\%)$ & $18(45 \%)$ & $17(42.5 \%)$ & $\mathrm{p}=0.368$ \\
Follow-up (months) & $9.3 \pm 7.7(1-36)$ & $32.9 \pm 12.6(8-50)$ & $\mathrm{p}<0.001$ \\
\hline
\end{tabular}

* Median

rectal injury $(2.5 \%)$. Both bleedings came from the DVC. The first one was controlled after conversion to the open approach and the last one was treated with intracorporeal suture. The bladder injury was recognized and treated by intracorporeal suture. On the other hand, the rectal injury was unrecognized in the intraoperative time and evolved with bloody anal discharge on postoperative day one, which led to an open colostomy.

Postoperative data are described in Table-3. Median time to discharge, early urinary continence and follow-up time were statistically better for Group 2 . No statistical difference was observed on early postoperative sexual function, evaluated by the vaginal penetration rate whether or not using sildenafil 100 mg.

The Table-4 shows no statistical difference in overall postoperative complications $(52.5 \%$ x $35 \%$; $p$ $=0.365)$. Nonetheless, sub-stratifying the complications, a statistical difference was observed by comparing the minor complications during the early and late postoperative time for each group.

The main complications observed in Group 1 were one case each of urinary sepsis, fecal and urinary peritonitis. The sepsis occurred on postoperative day (POD) 8 by Klebsiella pneumoniae despite preoperative negative urine culture and trans-operative use of parental ceftriaxone. The patient was readmitted and had an uneventful recovery after appropriate parenteral antibiotic therapy. The fecal peritonitis occurred on POD 4 due to fecal leakage by the rectal suture line performed intraoperatively. The patient evolved with peritonitis, sepsis and died on POD 35 even after colostomy and parenteral antibiotic therapy. The urinary peritonitis occurred due to urinary leakage from the posterior aspect of the UV anastomosis, leading to a $1500 \mathrm{cc}$ urine peritoneal collection. After open laparotomy and peritoneal drainage, the patient had an uneventful recovery.

In the Group 2, seven urinary leakages originating from the UV anastomosis occurred and were treated by prolonged bladder catheterization. Of those, six evolved with urinary strictures (bladder neck- 03; bulbar urethra- 02; and meatal urethra- 01), and had an uneventful recovery after appropriate treatment. A further urinary leakage due to the UV anastomosis evolved with a large retroperitoneal infiltration and was treated with open drainage, positioning of a tubular drain and prolonged bladder catheterization.

Lastly, the Table-5 shows the final oncological data. Comparing the results between groups 1 and 2, statistical difference was observed in the biochemical recurrence rate $(5 \% \times 20 \% ; \mathrm{p}=0.043)$, overall incidence of PSM $(10.3 \% \times 32.5 \% ; \mathrm{p}=0.016)$ and pathological stages (pT2: $94.8 \% \times 70 \%$ and pT3: $5.2 \%$ x $30 \% ; p=0.005)$. Nonetheless, no difference was observed when the incidence of PSM was correlated with the pathological stages. The majority of PSM in Group 1 occurred in pT2c (75\%), while this observation was more prevalent in pT3a in Group 2 $(61.5 \%)$. For pT3b, $100 \%$ of PSM occurred in both groups.

\section{COMMENTS}

According van Velthoven et al. (4) and Gill et al. (13), about $92 \%$ of uro-laparoscopic centers that currently use the extraperitoneal approach, started their laparoscopic programs using the transperitoneal 
Table 4-Comparison of postoperative complications and reoperations.

\begin{tabular}{lccc}
\hline & $\begin{array}{c}\text { Group 1 } \\
(\mathrm{n}=40)\end{array}$ & $\begin{array}{c}\text { Group 2 } \\
(\mathrm{n}=40)\end{array}$ & p Value \\
\hline Overall complications (before 30th POD): & $21(52.5 \%)$ & $14(35 \%)$ & $\mathrm{p}=0.365$ \\
Early complications (before 30th POD): & & & $\mathrm{p}<0.001$ \\
Minor - n (\%) & $4(10 \%)$ & - & \\
$\quad$ Perineal pain & $2(5 \%)$ & $7(17.5 \%)$ & \\
$\quad$ Abdominal wall hematoma & - & - & $\mathrm{p}=0.241$ \\
$\quad$ Urinary leakage & $1(2.5 \%)$ & - & \\
Major - n (\%) & $1(2.5 \%)$ & - & \\
$\quad$ Fecal peritonitis (death) & $1(2.5 \%)$ & $1(2.5 \%)$ & \\
Urinary peritonitis & - & & $\mathrm{p}=0.004$ \\
Urinary sepsis & & - & \\
Retroperitoneal urinary infiltration & & & \\
Late complications (after 30th POD) & & & \\
Minor - n (\%) & $9(22.5 \%)$ & $2(7.5 \%)$ & \\
UTI & $1(2.5 \%)$ & $2(5 \%)$ & \\
Bladder neck stricture & - & $1(2.5 \%)$ & \\
Urethral stricture & 0 & 0 & $\mathrm{p}=1.000$ \\
Urethral meatus stricture & $2(5 \%)$ & $2(5 \%)$ & $\mathrm{p}=1.000$ \\
Major - n (\%) & $1(2.5 \%)$ & - & \\
Reoperations: n (\%) & & & \\
Death & & & \\
\hline
\end{tabular}

$P O D=$ postoperative day; UTI = urinary tract infection.

route. In general, this observation can cause a bias on results when these accesses are compared in the same series. Such discrepancy in results can even be greater during the initial phase of a LRP program.

Perhaps the best way to overcome the LC in LRP is the incorporation of robotics in clinical practice (14). However, even in robotic LRP, a LC does exist and so far, controversies remain about the choice of the approach to use is these cases. Moreover, the high costs associated with this technique, make it a distant reality for developing countries. Therefore, continuous improvements in LRP technique are mandatory and identification of factors that can improve and shorten the LC is imperative to achieve better results.

The main goal of this retrospective study was to compare the perioperative complication rates of two distinct groups of patients operated each by the transperitoneal and extraperitoneal approaches during the initial phases of a LRP program. For this, each group was operated by only one urologist, having each a wide experience in retropubic radical prostatectomies and in more than 250 uro-laparoscopic surgeries. This study model, despite some points of criticism, was adopted to analyze the influence of the LC over the incidence of complications and to identify factors that could improve the results in this phase. Only Machado et al. (15) performed a similar study and observed better results with the extraperitoneal approach when compared with the transperitoneal route.

Observing the intraoperative data, the patients in Group 1 reached better surgical time and bled less than the ones in the Group 2 and these findings can be associated with the better working space and luminosity achieved with the transperitoneal access. 
Table 5 - Postoperative pathological data.

\begin{tabular}{lccc}
\hline & $\begin{array}{c}\text { Group 1 } \\
(\mathrm{n}=39)\end{array}$ & $\begin{array}{c}\text { Group 2 } \\
(\mathrm{n}=40)\end{array}$ & p Value \\
\hline Biochemical recurrence & $2(5 \%)$ & $8(20 \%)$ & $\mathrm{p}=0.043$ \\
Gleason score - n (\%) & & & $\mathrm{p}=0.365$ \\
$\quad 6(3+3)$ & $14(35 \%)$ & $21(52.5 \%)$ & \\
7 & $24(60 \%)$ & $16(40 \%)$ & \\
$\quad 7(3+4)$ & $19(47.5 \%)$ & $12(30 \%)$ & \\
$7(4+3)$ & $5(12.5 \%)$ & $4(10 \%)$ & \\
$8(3+5)$ & $1(2.5 \%)$ & $2(5 \%)$ & \\
$8(4+4)$ & - & $1(2.5 \%)$ & $\mathrm{p}=0.016$ \\
BPH & $1(2.5 \%)$ & - & $\mathrm{p}=0.005$ \\
Positive surgical margins - n (\%) & $4(10.3 \%)$ & $13(32.5 \%)$ & \\
Pathological stage - n (\%) & & & \\
T2 & $37(94.8 \%)$ & $28(70 \%)$ & \\
T3 & $2(5.2 \%)$ & $12(30 \%)$ & \\
\hline
\end{tabular}

$B P H=$ benign prostatic hyperplasia.

Nonetheless, two major complications were observed in Group 1, causing a urinary and fecal peritonitis, leading to the death of one patient. These results are the real reflex of the LC effect over each LRP program without any previous experience with LRP.

Urinary leakage can occur up to $28 \%$ in LRP during the LC (16-19). Of note, all seven early minor complications observed in the Group 2 were represented by urinary leakages, while only one was observed in the Group 1, which was considered a major complication. The majority of these cases evolved to urinary strictures and needed surgical treatment. In general, urinary leakages occur due to non-well aligned suture lines, surgery in prostates $>60$ grams, use of interrupted sutures and when the extraperitoneal access is chosen $(18,19)$. In general, tension over the UV anastomosis is considered higher when the extraperitoneal access is used instead of the transperitoneal route, because the bladder remains stacked on the abdominal wall by the urachus (20). In fact, based in these observations, the authors recommend the use of the UV running suture since the initial phases of the LC. Likewise, to rule out urinary leakage, filling the bladder in with $200 \mathrm{cc}$ of saline after finishing the UV anastomosis is recommended.
Each group had one major complication on early postoperative time related to urinary leakage, as well as one rectal injury. In Group 1, both complications evolved to peritonitis needing reoperation, culminating in one death. On the other hand, these findings in the Group 2 evolved with less severity and went well after reoperation.

The incidence of rectal injury occurs in $1.8 \%$ $6 \%(8,21)$ and is more common during the $\operatorname{LC}(8,21)$. According Touijer et al. (22) and Martinez-Piñeiro et al. (19), the majority of injuries occur during the apical dissection. Although the rectal injury had been recognized and sutured during the intraoperative time in one patient in Group 1, the injury presented a fecal leakage on POD 4, leading to peritonitis and death. This fact was attributed to the use of the harmonic shears to dissect the posterior aspect of the prostate, near the apex. Probably, an invisible thermal injury occurred in the rectal wall during the surgery and a later wall necrosis developed, leading to the fecal leakage $(19,22)$.

Important to notice that rectal injury can occur whatever the approach, but this complication tends to have a worse outcome when the transperitoneal route is adopted. The authors strongly recommend the 
use of cold shears instead of the use of any kind of thermal shears to dissect this area to avoid this major complication, no matter which laparoscopic approach chosen.

Bladder injury is considered a rare event and is more common during the $\mathrm{LC}$, reaching $8 \%(17,23)$. It can occur with both approaches and usually the injury is recognized and sutured during the surgery. In general, all injuries have an uneventful recovery after appropriate treatment.

Perineal pain is a rare event and was observed in four patients in Group $1(10 \%)$. This was attributed to hyper abduction of legs in order to place the laparoscopic rack in between. No further cases of this type of complication were observed after discontinuation of this practice.

Epigastric artery injury occurs in about 2\% $-6.2 \%$ of cases and generally is associated with trocar insertion during transperitoneal surgeries $(17,23)$. This injury rarely occurs during ELRP, because the vessels are easily seen after the extraperitoneal space has been created. The authors suggest puncturing before the site of trocar placement with a fine needle in order to verify the route, avoiding this injury. Also is recommended to have a Carter-Thomason device readily to use if necessary.

Finally, urinary tract infection occurs in $1.4 \%-2.8 \%$ in all cases of LRP, despite of antibiotic prophylaxis $(2,24)$. Generally, these infections are caused by prolonged indwelling catheter use and/or inappropriate antibiotic prescription. Currently, the authors suggest the use of quinolones for 14 days after the hospital discharge and the urethral catheter removal as soon as possible, around the postoperative day 7.

The LRP is considered the most challenging laparoscopic surgery in urology. The greatest drawback of this surgery is its steep LC and consequently the possibility of major complications to occur and weak functional results during this time. Moreover, the initiation of a LRP program demands great caution in order to not overcome the main objective of this surgery: the cure. Therefore, continuous improvements and training are mandatory to achieve better outcomes. Based in our results, there was no difference in the incidence of perioperative complications whatever the approach used to operate both groups during the LC. The incidence and severity of major complications were higher when the transperitoneal approach was adopted.

\section{CONCLUSIONS}

The overall complication rate was similar in both approaches. Minor complications occurred in both groups and tended to complete resolution after appropriate treatment. The higher incidence of urinary leakage in Group 2 was directed associated with the interrupted UV anastomosis and indirectly linked with the extraperitoneal route. The transperitoneal approach presented more serious complications during the early postoperative time and this fact is attributed to the potential chance of intraperitoneal peritonitis not observed with the extraperitoneal approach.

\section{CONFLICT OF INTEREST}

None declared.

\section{REFERENCES}

1. Guillonneau B, Cathelineau X, Barret E, Rozet F, Vallancien G: Laparoscopic radical prostatectomy. Preliminary evaluation after 28 interventions. Presse Med. 1998; 27: 1570-4.

2. Bollens R, Vanden Bossche M, Roumeguere T, Damoun A, Ekane S, Hoffmann P, et al.: Extraperitoneal laparoscopic radical prostatectomy. Results after 50 cases. Eur Urol. 2001; 40: 65-9.

3. Porpiglia F, Terrone C, Tarabuzzi R, Billia M, Grande $\mathrm{S}$, Musso F, et al.: Transperitoneal versus extraperitoneal laparoscopic radical prostatectomy: experience of a single center. Urology. 2006; 68: 376-80.

4. van Velthoven RF: Laparoscopic radical prostatectomy: transperitoneal versus retroperitoneal approach: is there an advantage for the patient? Curr Opin Urol. 2005; 15: 83-8.

5. Eden CG, King D, Kooiman GG, Adams TH, Sullivan ME, Vass JA: Transperitoneal or extraperitoneal laparoscopic radical prostatectomy: does the approach matter? J Urol. 2004; 172: 2218-23.

6. Hoznek A, Antiphon P, Borkowski T, Gettman MT, Katz R, Salomon L, et al.: Assessment of surgical 
technique and perioperative morbidity associated with extraperitoneal versus transperitoneal laparoscopic radical prostatectomy. Urology. 2003; 61: 617-22.

7. Poulakis V, Dillenburg W, Moeckel M, de Vries R, Witzsch U, Zumbé J, et al.: Laparoscopic radical prostatectomy: prospective evaluation of the learning curve. Eur Urol. 2005; 47: 167-75.

8. Ghavamian R, Schenk G, Hoenig DM, Williot P, Melman A: Overcoming the steep learning curve of laparoscopic radical prostatectomy: single-surgeon experience. J Endourol. 2004; 18: 567-71.

9. Fabrizio MD, Tuerk I, Schellhammer PF: Laparoscopic radical prostatectomy: decreasing the learning curve using a mentor initiated approach. J Urol. 2003; 169: 2063-5.

10. Guillonneau B, Vallancien G: Laparoscopic radical prostatectomy: the Montsouris technique. J Urol. 2000; 163: 1643-9.

11. Stolzenburg JU, Neuhaus J, Horn LC, et al.: Inter- and Intrafascial dissection technique of nerve-sparing radical prostatectomy. In: Stolzenburg JU, Gettman MT, Liatsikos EN (ed.), Endoscopic extraperitoneal radical prostatectomy. Laparoscopy and robot-assisted surgery. Berlin, Springer. 2007; pp. 20-23.

12. Van Velthoven RF, Ahlering TE, Peltier A, Skarecky DW, Clayman RV: Technique for laparoscopic running urethrovesical anastomosis:the single knot method. Urology. 2003; 61: 699-702.

13. Gill IS, Clayman RV, Albala DM, Aso Y, Chiu AW, Das S, et al.: Retroperitoneal and pelvic extraperitoneal laparoscopy: an international perspective. Urology. 1998; 52: 566-71.

14. Mavrich Villavicencio H, Esquena S, Palou Redorta J, Gómez Ruíz JJ: Robotic radical prostatectomy: overview of our learning curve. Actas Urol Esp. 2007; 31: 587-92.

15. Machado MT, Juliano RV, Tristão RA, Watanabe M, Forseto Jr PH, Wroclawski ER: Laparoscopic prostatectomy: a comparative study between transperitoneal and extraperitoneal approaches during the learning curve. Einstein. 2007; 5: 203-8.

16. Ghavamian R, Knoll A, Boczko J, Melman A: Comparison of operative and functional outcomes of laparoscopic radical prostatectomy and radical retropubic prostatectomy: single surgeon experience. Urology. 2006; 67: 1241-6.

17. Amón Sesmero JH, Estébanez Zarranz J, Conde Redondo C, Rodríguez Toves A, Robles Samaniego A, Valle del González N, et al.: Intraoperative complications and morbidity of laparoscopic radical prostatec- tomy (LRP) during the learning curve. Arch Esp Urol. 2004; 57: 417-24.

18. Mochtar CA, Kauer PC, Laguna MP, de la Rosette JJ: Urinary leakage after laparoscopic radical prostatectomy: a systematic review. J Endourol. 2007; 21: 1371-9.

19. Martinez-Piñero L, Pérez-Chrzanowska H, Gonzaléz JS, de La Peña JJ. Handling complications in laparoscopic radical prostatectomy. In: La Rossete JJMCH, Gill IS (ed.), Laparoscopic urologic surgery in malignancies. 1st ed. Berlin: Springer, 2005: p. 185-200.

20. Brown JA, Rodin D, Lee B, Dahl DM: Transperitoneal versus extraperitoneal approach to laparoscopic radical prostatectomy: an assessment of 156 cases. Urology. 2005; 65: 320-4.

21. Abbou CC, Salomon L, Hoznek A, Antiphon P, Cicco A, Saint F, et al.: Laparoscopic radical prostatectomy: preliminary results. Urology. 2000; 55: 630-4.

22. Touijer K, Trabulsi E, Hassen W, Guillonneau B: Laparoscopic radical prostatectomy: The transperitoneal antegrade approach. In: de La Rossete JJ. MCH, Gill IS (ed.), Laparoscopic urologic surgery in malignancies. 1st ed. Berlin, Springer. 2005; pp. 141-8.

23. Martorana G, Manferrari F, Bertaccini A, Malizia M, Palmieri F, Severini E, et al.: Laparoscopic radical prostatectomy: oncological evaluation in the early phase of the learning curve comparing to retropubic approach. Arch Ital Urol Androl. 2004; 76: 1-5.

24. Gregori A, Simonato A, Lissiani A, Bozzola A, Galli S, Gaboardi F: Laparoscopic radical prostatectomy: perioperative complications in an initial and consecutive series of 80 cases. Eur Urol. 2003; 44: 190-4; discussion 194.

Accepted after revision:

December 20, 2009

\section{Correspondence address:}

Dr. Tibério M. Siqueira, Jr

Av. Agamenon Magalhães, 4775 / 201

Recife, Pernambuco, 50070-160, Brazil

Fax: + 5581 2125-7402

E-mail: tiberiojr@uol.com.br 